\section{Mechanism of the Primary Photodissociation Process of Organic Molecules}

Is a recent letter to NATURE ${ }^{1}$, Bergmann and Samuel advance a theory of photodecomposition of organic molecules according to which two bonds are fissured simultaneously, not by the splitting of two single bonds but by a transition to the repulsive state which corresponds to a reduction of valency of the central atom resulting from the re-formation of the $s^{2}$ group of this atom.

This conclusion is not new : it was shown in 1933 by Norrish, Crone and Saltmarsh ${ }^{2}$ that the ketene molecule is decomposed photochemically according to the equation

$$
\mathrm{CH}_{2}: \mathrm{CO} \rightarrow \mathrm{CH}_{2}+\mathrm{CO}\left({ }^{1} \Sigma\right),
$$

and that the energy of the photolysing quantum (74 kgm. cal.) is insufficient to rupture the double bond (say, $167 \mathrm{kgm}$. cal.) unless the $\mathrm{CO}$ is liberated as normal carbon monoxide rather than as free carbonyl. Similar considerations were held to apply to the photolysis of diazomethan $e^{3}$.

The idea was then tentatively extended to ketones ${ }^{4,5}$; for example,

$$
\mathrm{CH}_{3} \mathrm{COC}_{2} \mathrm{H}_{5} \rightarrow \mathrm{CH}_{3}+\mathrm{C}_{2} \mathrm{H}_{5}+\mathrm{CO}\left({ }^{1} \Sigma\right),
$$

but it was emphasized that there was no evidence to show in these cases whether the two alkyl radicals are eliminated simultaneously or one rapidly after the other. Since then it has transpired that in the case of acetone the elimination takes place successively ${ }^{6}$; this was later confirmed more generally since in paraffinoid solution it was shown that the free radical RCO formed can be hydrogenated to aldehyde? at temperatures exceeding $60^{\circ} \mathrm{C}$.

The apparent result of equation (2) is thus due to the instability of the acyl group, which at $60^{\circ}$ and upwards readily decomposes :

$$
\mathrm{RC} \mathrm{C} \rightarrow \mathrm{R}+\mathrm{CO}\left({ }^{1} \Sigma\right),
$$

presumably owing to the tendency of the carbonyl of the radical to revert to the repulsive singlet state.

These results have not been taken into consideration by Bergmann and Samuel, while the photolyticequations which they suggest are unsupported by evidence, and in some cases in disagreement with fact. All the evidence shows that ketones and aldehydes do not decompose by analogy with their equations. In the region of predissociation, formaldehyde yields molecular hydrogen and carbon monoxide in one act ${ }^{8,9}$, while the $\alpha \alpha$ dicarbonyl substance glyoxal decomposes according to the equation ${ }^{10}$

$$
2 \mathrm{HCO} . \mathrm{CHO} \rightarrow \mathrm{CO}+\mathrm{CH}_{2} \mathrm{OH} . \mathrm{CO} . \mathrm{CHO} \text {. }
$$

The decomposition of methyl glyoxal is analogous and diacetyl appears to be still more complicated, and none of the products can be derived from equations of the type suggested by Bergmann and Samuel.

It should be noted that so far as aldehydes and ketones are concerned, the heats of the reactions

$$
\begin{aligned}
& \mathrm{RCOR} \rightarrow \mathrm{R}+\mathrm{R}+\mathrm{CO}\left({ }^{1} \Sigma\right), \\
& \mathrm{RCOR} \rightarrow \mathrm{R}+\mathrm{R} \dot{\mathrm{C} O},
\end{aligned}
$$

though at present suffering from some uncertainty, are not very different, and that the threshold of continuous absorption is not sufficiently precise to be correlated with either, even supposing they were known accurately.

The mechanism of the photodissociation of $\mathrm{SnI}_{4}$ and $\mathrm{BiI}_{3}$ was first elucidated experimentally by Terenin ${ }^{11}$. Samuel and Parti ${ }^{12}$ employ a modified mechanism to explain the long wave-length limit of the absorption spectrum of $\mathrm{CI}_{4}$. The good agreement they obtain is dependent upon an uncertain assumption about the ratio of the heats of formation of $\mathrm{CHal}_{2}$ and $\mathrm{CHal}_{4}$ and also upon the use of a value $156 \cdot 2 \mathrm{k}$.cal. for the heat of sublimation of carbon. Reliable sources ${ }^{13,19}$ now consider the latter to be about 124 k.cal., a value which would completely upset their agreement. This has already been pointed out by Cherton ${ }^{14}$, and the same remark applies to their other calculations.

Finally, it cannot be too strongly urged that with polyatomic molecules the principle of Franck, Sponer and Teller ${ }^{15}$ comes into operation, and that the onset of predissociation is properly shown by the threshold of fluorescence rather than by the threshold of diffuseness ${ }^{16}$. With formaldehyde the former is at about $3700 \mathrm{~A}$., and the latter at $2750 \mathrm{~A}$., while the photochemical yield is unity on both sides of the limit of diffuseness, and the products unchanged ${ }^{17}$. Herzberg and Franz ${ }^{18}$ set the true limit of predissociation at a wave-length longer than $3000 \mathrm{~A}$. No evidence in support of Bergmann and Samuel is therefore forthcoming in the case of formaldehyde.

Generalizations of the type advocated by Bergmann and Samuel are unsafe because of the uncertainty of the precise values of the energy of many chemical bonds, and also because of the doubt as to the proper interpretation to be put upon diffuseness in the spectra of polyatomic molecules. They cannot be safely accepted in the absence of supporting chemical evidence.

\section{R. G. W. NORRISH.}

\section{Laboratory of Physical Chemistry, Cambridge. May 31.}

\footnotetext{
Bergmann and Samuel, Nature, 141, 832 (1938).

2 Norrish, Crone and Saltmarsh, J. Chem. Soc., 1533 (1933).

3 Norrish, Trans. Farad. Soc., 30, 103 (1934).

4 Norrish and Appleyard, J. Chem. Soc., 874 (1934).

5 Norrish, Crone and Saltmarsh, J. Chem. Soc., 1456 (1934)

- Spence and Wild, J. Chem. Soc., 352 (1937).

? Norrish and Bamford, NATURE, 140, 195 (1937).

${ }^{8}$ Locker and Patat, Z. Phys. Chem., B, 27, 431 (1935).

- Kirkbride and Norrish, Trans. Farad. Soc., 27, 404 (1931).

10 Norrish and Griffiths, J. Chem. Soc., 2829 (1928).

11 Terenin, NATuRE, 135, $543(1935) ;$ C.R., Acad. Sci. U.R.S.S., 1, 482 (1935)

12 Samuel and Parti, Proc. Phys. Soc., 49, 568 (1937).

13 Herzberg, Herzfeld and Teller, J. Phys. Chem., 41, 325 (1937).

1 Cherton, Bull. Soc. Roy. Sci. Liéje, 3, 234 (1938).

15 Franck, Sponer and Teller, Z. phys. Chem., B, 18, 88 (1932).

so Norrish, Acta phys. Chem. U.R.S.S., 3, 171 (1935).

17 Norrish and Kirkbride, J. Chem. Soc., 1518 (1932).

${ }^{18}$ Herzberg and Fraunz, Z. Phys., 76, 720 (1932).

18 Goldfinger and Jeunehomme, Trans. Farzd. Sxe., 32, 1591 (1936
}

\section{Possibility of the Formation of Cyclols from Simple Peptides}

IN a series of communications in Nature, Dr. D. M. Wrinch ${ }^{1}$ has put forward a new hypothesis on the structure of certain proteins-the 'cyclol-theory'. According to this, peptide chains should be capable 